\title{
La Teoría: Aproximaciones Pedagógicas y Socioculturales
}

\author{
José Enrique Juncosa Blasco \\ Luis Fernando Garcés Velásquez
}

\section{SciELO Books / SciELO Livros / SciELO Libros}

JUNCOSA BLASCO, J. E., and GARCÉS VELÁSQUEZ, L. F. La Teoría: Aproximaciones Pedagógicas y Socioculturales. In: ¿Qué es la teoría? Enfoques, usos y debates en torno al pensamiento teórico [online]. Quito: Editorial Abya-Yala, 2020, pp. 179-228. ISBN: 978-9978-10-543-6. http://doi.org/10.7476/9789978105788.0004.

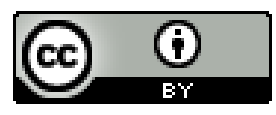

All the contents of this work, except where otherwise noted, is licensed under a Creative Commons Attribution 4.0 International license.

Todo o conteúdo deste trabalho, exceto quando houver ressalva, é publicado sob a licença Creative Commons Atribição 4.0.

Todo el contenido de esta obra, excepto donde se indique lo contrario, está bajo licencia de la licencia Creative Commons Reconocimento 4.0. 


\section{Capítulo III LA TEORÍA: APROXIMACIONES PEDAGÓGICAS Y SOCIOCULTURALES}

\section{Introducción}

El presente capítulo selecciona tres autores muy puntuales no relacionados entre sí, que describen desde perspectivas y tradiciones de pensamiento muy distintas no la teoría en sí, en sus componentes y elementos que la constituyen, sino las características del pensamiento o conocimiento teórico considerado de manera más amplia y general. Se trata de Gilbert Ryle, Magoroh Maruyama y Kieran Egan, a quienes consideramos relevantes porque, a diferencia de los aportes de la epistemología y de la filosofía de la ciencia ya revisados, proporcionan una aproximación psicosocial y cultural con implicaciones para la gestión del conocimiento, para comprender la heterogeneidad de la producción teórica en la ciencia y las concepciones en torno al desarrollo del pensamiento en instituciones educativas.

Gilbert Ryle (1900-1976) fue profesor de filosofía metafísica de la Universidad de Oxford y miembro de la escuela Analítica. Sus puntos de vista y postura crítica en torno al "teorizar" se condensan en la obra El concepto de lo mental ([1949] 2005), en la que basamos nuestra sistematización. "Teorizar" es una capacidad ejecutoria aprendida en la que intervienen habilidades y desempeños puntuales transmitidos e incorporados comprensivamente mediante el "discurso didáctico". La "teoría” y el "teorizar" son comportamientos 
públicos y, por ello, observables que tienen lugar "fuera de los individuos" ("entre los individuos") y no, como se suele suponer, en algo como la mente, considerada un centro intraindividual que comanda operaciones intelectuales. Por ser una actividad intersubjetiva sujeta a reglas del juego, el teorizar, al igual que muchas otras actividades humanas, está sujeta al aprendizaje.

Magoroh Maruyama (1929), formado en Matemáticas (Universidad de California) y en Epistemología Cultural (Universidad de Lund), fue profesor visitante de ciencias administrativas en la Universidad del Sur de Illinois cuando escribió su artículo más conocido "Mindscapes and Science Theories" ("Paisajes mentales y teorías de la ciencia"), publicado por la revista Current Anthropology en octubre de 1980. En él, recoge investigaciones anteriores para afinar la caracterización, desde la antropología de la ciencia, de los diversos "patrones cognitivos/cogitativos/perceptivos" en cuyo marco las teorías científicas se producen, expresan y funcionan de distinta manera. Consideramos que su aproximación es útil por concebir los escenarios académicos como espacios heterogéneos donde, a pesar de que la teoría constituye su lenguaje común, esta se despliega de manera distinta según diferencias culturales marcadas por las disciplinas o las instituciones.

Kieran Egan (1942) es un filósofo de la educación contemporáneo $^{38}$ y la obra que sistematizaremos ha sido publicada primero en inglés en 1997 y su versión en español, en el año 2000, con el título Mentes educadas. Cultura, instrumentos cognitivos y formas de comprensión. La intencionalidad de su propuesta, a diferencia de to-

38 De origen irlandés, formado en Inglaterra y radicado posteriormente en Estados Unidos, donde se doctoró en Filosofía de la Educación en la Universidad de Cornell. Actualmente, labora en la Simon Fraser University de Canadá e integra la Academia Nacional de Educación de Estados Unidos. 
das las que serán revisadas en este capítulo, es pedagógica en todo el sentido de la palabra porque apunta al proyecto de cultivar la imaginación en el desarrollo intelectual de los niños, adolescentes y jóvenes mediante la inclusión en la educación formal de diversas formas de comprensión atesoradas a lo largo de la historia de la cultura. Su propuesta sigue de cerca la inspiración vygotskiana, según la cual el aprendizaje es un proceso social atado a la misma dinámica del lenguaje y son las mediaciones sociales las que lo hacen posible. Por otro lado, resignifica la idea de recapitulación de Spencer, de manera tal que el estudiante no recapitula los contenidos a lo largo del itinerario educativo, sino las formas de pensar propias de la historia de la cultura. La escuela es el escenario de ejercicio y cultivo de esas múltiples formas de comprensión que incluyen instrumentos intelectuales específicos. El lenguaje teórico es, apenas, uno de estos, entre otros.

\section{Gilbert Ryle: teorizar y teoría como actuaciones discursivas}

En El concepto de lo mental Ryle describe la teoría y el teorizar como expresiones del actuar inteligente observable únicamente a partir de los comportamientos públicos inteligentes y desde la metodología propia de la filosofía del lenguaje ordinario (Dennett, 2005, p. 18). A partir de cómo ambos términos se usan y aparecen en el lenguaje corriente es posible identificar exclusiones, asociaciones y parentescos con otros términos vinculados con la inteligencia, como el de "actuar inteligentemente", "poseer conocimiento", "actividad intelectual" y otros que refieren adjetivaciones y desempeños intelectuales asociados. Su aporte es vigente y reviste interés para nosotros porque, en su momento - y todavía hoy — contribuyó a cuestionar el intelectualismo cartesiano que, a pesar de todas las críticas, goza todavía de buena salud en la academia en aquellos no pocos casos en 
los que ampara la doctrina oficial que otorga primacía a las teorías y los conceptos y cuando su posesión se considera condición previa del pensar y el actuar inteligentes.

La presente sistematización de la propuesta de Ryle articula dos momentos: el primero de los cuales desarrolla su crítica a la leyenda intelectualista cartesiana, proponiendo que las acciones inteligentes son formas públicas de actuar que implican capacidades aprendidas y habilidades. La segunda desplegará las descripciones en torno al teorizar y la teoría, así como el correlato de sus formas discursivas.

\section{La práctica eficiente precede a la teoría}

El punto de partida de Ryle es desarmar el dualismo cartesiano y declara inviable la segmentación polarizada mente-cuerpo, ya sea porque se trata de un error categorial (pone en el mismo plano categorías que pertenecen a órdenes distintos de la existencia), ya porque el dualismo atribuye a la mente, sin querer y resultado de su propia inviabilidad, leyes análogas a las que rigen el mundo físico o porque hace de esta un fantasma en la máquina del cuerpo. A continuación de la crítica, desglosaremos la distinción entre "saber hacer" y "saber que..." desde la cual define la actuación inteligente y construye las bases de su edificio argumental.

\section{En contra del dualismo cartesiano y la leyenda intelectualista}

Comencemos por lo primero. Según Ryle (2005, pp. 25 y ss.), el dualismo cartesiano se funda en la doble composición de la persona humana constituida por un cuerpo y una mente, instancias opuestas e irreductibles entre sí, ambas en relación de oposición contrastiva y jerarquizada, deberíamos añadir. El cuerpo remite al espacio y sus procesos pueden ser observados y controlados por observa- 
dores externos y, al ser observable, la vida corporal es pública y sus funciones reductibles a leyes mecánicas o físicas. La mente no decurre en el espacio sino en el tiempo y sus funciones no están sujetas a leyes mecánicas o físicas. Al no ser observables por otros, son patentes y accesibles a la conciencia de cada individuo.

Así, la leyenda intelectualista forja la idea de individuos que viven dos tipos de existencia, "dos vidas", "dos mundos", a la manera de "historias paralelas" (la cara y cruz de una moneda), en relación de "oposición polar" (p. 27), signadas por dos tipos de acontecimientos: los del mundo físico y los del mundo mental. La mente "no es observable por otro y su desarrollo es privado. Solo yo puedo tener conocimiento directo de los estados y procesos de mi propia mente" (p. 25), al punto que, en cosas de la mente, somos como Robinson Crusoe (p. 27) ${ }^{39}$. La conciencia, la autoconciencia y la introspección permitirían al individuo acceder directamente a su mundo mental con mayor claridad y distinción que con las que es capaz de acceder al mundo físico pero con la imposibilidad de acceder al mundo interno de los otros ${ }^{40}$. El acceso mediante la actuación lingüística y verbal no es posible ya que estas interacciones están del lado de las leyes físicas y nada dicen de la mente.

La crítica de Ryle apunta contra la ilusión cartesiana de que las operaciones mentales son accesibles al individuo del mismo modo, pero con mayor claridad respecto a los acontecimientos físicos. Pero no puede obviar responder a la pregunta: ¿de qué manera construi-

39 Para Ryle el espacio es el campo común que conecta lo que sucede entre un cuerpo y otro; no es así para los hechos mentales que "acaecen en ámbitos aislados, las 'mentes', y no existe conexión causal directa entre lo que le sucede a una mente y lo que le pasa a otra..." (p. 27).

40 "La soledad absoluta es el destino inevitable del alma. Solo nuestros cuerpos se pueden encontrar" (p. 29). 
184

mos conceptos generales referidos a facultades y operaciones mentales de todos los individuos si no son observables por otros? La única respuesta posible de la leyenda intelectualista es postular la existencia de la mente, expresión de un lugar que corresponde a la "geografía lógica" en el que subyacen procedimientos y producciones mentales que anticipan las acciones. La mente sería ese centro de operaciones oculto e inaccesible que produce abstracciones, algo así como lo que entendía Popper, inspirado en Frege, al postular la existencia de un núcleo productor de operaciones mentales.

Dando un paso más, Ryle proporciona una metáfora para ilustrar el error que plantea la segmentación cuerpo-mente y consiste en el dogma del fantasma en la máquina (2005, pp. 29 y ss.), porque conduce a concebir a la persona como un fantasma inserto en la máquina, pero sujeto al fin y al cabo a procesos no mecánicos, según los cuales "las leyes de lo mental deben explicar las operaciones no espaciales de la mente como efecto de otras operaciones no espaciales" (p. 33). Parecería que las leyes causales abarcan también los procesos mentales, aunque de distinto tipo que las leyes físicas. Tal concepción da lugar a la hipótesis paramecánica (la mente también posee dinámicas del tipo "máquina”), conclusión contradictoria a la que no puede escapar el dualismo cartesiano cuyo desliz culmina en considerar que la mente es, análogamente, una máquina. En consecuencia, a pesar del contraste mente-cuerpo, el determinismo de las leyes físicas se cierne también sobre las leyes de la mente.

Las operaciones mentales tuvieron que ser descritas negando las características atribuidas a los cuerpos; no están en el espacio, no son movimientos, no son modificaciones de la materia, no son accesibles a la observación públicas. Las mentes no son trozos de un mecanismo de relojería. Son simplemente trozos de un no mecanismo [...] la mente humana no es meramente un fantasma 
enjaezado a una máquina, sino que es en sí misma una máquina espectral. (2005, p. 33)

Para Ryle no es posible concebir la persona constituida por dos realidades en oposición, los procesos físicos por un lado y los procesos mentales por otro, pues plantear esa segmentación obedece a un error categorial. La postulación de una "oposición polar entre ellas es sostener que ambos términos poseen el mismo tipo lógico”. Lo corporal y lo mental no son términos de una misma categoría. Ambos son distintos en el sentido de que no cabe entre ellos ni la absorción ni la exclusión, y aceptar que se tratan de categorías diferentes lleva a superar el dualismo mente-materia (p. 36) y a evitar la subsunción de lo mental en la materia (materialismo) y viceversa (idealismo). Ambos términos "ofrecen dos maneras distintas de existir; algo así como 'crecer' tiene sentidos diferentes en la 'marea está creciendo', 'las esperanzas están creciendo', y 'la edad promedio de mortalidad está creciendo"” (p. 36).

\section{Teorizar y teoría desde la distinción "saber hacer" y "saber que..."}

A continuación de la crítica del dualismo cartesiano, plantea la distinción clave entre dos maneras de conocer que no siempre van ni tienen por qué ir juntas: el "saber hacer" y el "saber que..." ${ }^{41}$, siendo lo primero la actuación de disposiciones (capacidades y habilidades) aprendidas del individuo para actuar inteligentemente; y lo segundo, el conocimiento consciente y puntual de normas, prin-

41 El capítulo II de su libro El concepto de lo mental lleva por título, precisamente, "Saber hacer y saber que...", y cuya traducción literal del inglés corresponde a "Saber cómo y saber qué". Pero en español, preferimos decir que "Juan sabe tocar piano" y no "Juan sabe cómo tocar el piano" (el giro inglés usual). Con respecto a los puntos suspensivos de "saber que..." se entiende que deben ser llenados por proposiciones. (Ver nota del traductor, en Ryle, 2005, p. 39). 
cipios y criterios. Con base en esta distinción, Ryle expresa de la siguiente manera la tesis central de su edificio argumental: “... el ejercicio práctico de la inteligencia no puede ser analizado en términos de una operación en serie que consiste en considerar prescripciones para luego ejecutarlas" (p. 54).

En efecto (y el ejemplo es nuestro), conocer la sintaxis y la gramática de una lengua indígena ("saber que...") no implica necesariamente hablarla ("saber hacer"). Asimismo, muchos — la mayoría- de quienes hablan fluidamente el kichwa ("saber hacer") no son conscientes de las normas gramaticales subyacentes en sus ilocuciones ("saber que...”). Seguramente sus interacciones verbales no fluyen según el esquema tal que los interlocutores previamente se dictan a sí mismos la regla gramatical para luego construir "en su cabeza” la oración y recién expresar a los participantes de la conversación el enunciado que quieren compartir. De hecho, hablamos e interactuamos verbalmente sin anticiparnos las reglas gramaticales sino, y simplemente, ejecutándolas, actuándolas. El correlato de la tesis fundamental para los términos "teoría" y "teorizar", que pretendemos profundizar descriptivamente, se expresa de la siguiente manera:

La práctica eficiente precede a la teoría [...] En consecuencia, es posible llevar a cabo inteligentemente ciertas operaciones sin que sea posible tener en cuenta las proposiciones que determinan cómo ejecutarlas. Algunas acciones inteligentes no están reguladas por el conocimiento previo de los principios que las rigen. (Ryle 2005, p. 44)

El distinguir entre dos sentidos diferentes del saber, en tanto "saber hacer" y "saber que...", deshabilita la posibilidad de una instancia que define las acciones inteligentes de operaciones internas anteriores del tipo "planear qué hacer". Por ello, no es admisible concebir algo así como la "mente" humana, cual si fuera un comando de operaciones intelectuales (el fantasma en la máquina) que dicta des- 
187

de las normas a cada paso de la actuación. Con esta distinción, Ryle da otro golpe que desbarata la "doctrina oficial" (de la ciencia) y de la persistente "leyenda intelectualista" que, en cambio, identifica el "saber hacer" con el "saber que...", sobre la base de que

toda actuación inteligente presupone la observancia de reglas o la aplicación de criterios. Se sigue de ello que toda operación considerada inteligente debe ser precedida por un reconocimiento intelectual de esas reglas o criterios, esto es, que el sujeto debe primero reconocer internamente ciertas proposiciones acerca de lo que debe hacer (a veces denominadas "máximas", "imperativos", o "proposiciones regulativas") para comportarse —-solo después- de conformidad con tales dictados. (2005, p. 43)

En realidad, la inteligencia es un comportamiento y un atributo de la actuación; solo el actuar es inteligente y se atribuye el adjetivo "inteligente" a una persona que actúa inteligentemente. La persona inteligente "sabe hacer" en tanto que aquella que "sabe" no necesariamente "sabe hacer"; no siempre se desempeña acorde con ese saber. La tesis de Ryle posibilita trasladar explícitamente la primacía del "saber hacer" al ámbito pedagógico, al definirla como capacidad aprendida desde la observación que conduce a la práctica o a partir la enseñanza, que consiste en asimilar ejecutorias y actuar reglas de juego, tal como sucede en los siguientes ejemplos proporcionados por el mismo Ryle:

Pero podría ser posible que un niño aprendiera a jugar al ajedrez sin oír hablar de reglas en ningún momento. Observando los movimientos hechos por otros jugadores y advirtiendo cuáles son permitidos y cuáles no, podría adquirir el arte de jugar correctamente sin llegar a ser capaz de exponer las prescripciones que definen "correcto" e "incorrecto". Las reglas de los juegos de frío-caliente y del escondite, y las reglas elementales de la gramática y de la lógica, se aprenden de esta manera. Aprendemos a hacer mediante la 
práctica, ayudados por la crítica y el ejemplo, aunque a menudo sin recibir lección alguna sobre la teoría. (2005, p. 55)

El "saber hacer" es una forma de acción compleja, accesible a partir de lo que se puede observar: el comportamiento manifiesto y observable, pero es necesario ir más allá de él no como quien busca causas ocultas, "sino aptitudes, habilidades, hábitos, propensiones e inclinaciones" (p. 59). Las acciones inteligentes son aptitudes complejas que requieren de un conjunto de habilidades. El aprendizaje del actuar inteligente convoca la distinción y la relación entre tres términos importantes: la aptitud (capacity), el hábito y la habilidad (ability) de tal forma que la aptitud para aplicar reglas es una disposición adquirida resultado de la práctica (p. 56). La aptitud resuelve los problemas pensando y corrigiendo el paso siguiente, a diferencia de la habilidad que es de orden mecánico, como quien usa "hábilmente" la calculadora para resolver una operación matemática.

La aptitud no es un hábito, ya que se cultiva por el adiestramiento, en tanto que el hábito es un condicionamiento producto de la rutina adquirida por la repetición. Aunque el hábito está presente en algunas habilidades, no es una aptitud, ya que esta última es modificable: "es de la esencia de la acción inteligente ser modificada por las que la preceden. El sujeto está siempre aprendiendo..." (Ryle, 2005, p. 56). La aptitud, en tanto capacidad modificable y modificadora, produce innovación pues supone la capacidad de torcer el rumbo y enriquecer las posibles respuestas ante nuevas situaciones (p. 61).

Las aptitudes inteligentes son complejas también en otro sentido, pues no implican disposiciones uniformes en todos los individuos ni el mismo grado de competencia ni de ejecutorias ni maneras de actuarlas. Así, las aptitudes inteligentes revisten "una amplia gama de actualizaciones más o menos disímiles" (p. 69) entre los individuos. Aunque todos conocen las mismas reglas del ajedrez, la performance 
de cada uno es distinta y cada quien las actualiza de diversa manera. Incluso quien observa jugar el ajedrez participa de la misma aptitud de manera diferente en tanto observador crítico porque ha asimilado las reglas, del mismo modo que aquel que sabe de armonía es capaz de apreciar, sin ejecutar, una sinfonía siguiendo la partitura.

Al tratarse de una forma de proceder, el aprender aptitudes requiere del adiestramiento y es producto del desempeño concreto. Por lo tanto, no equivale a adquirir información. Así, el aprendizaje no procede desde dentro hacia afuera (desde los principios que se actualizan de un centro de operaciones: la mente), sino de afuera hacia adentro, pro medio de su despliegue público ("Aprendo con la actividad del otro"), tal como sucede cuando aprendemos las leyes de la lógica o del juego del ajedrez hasta que se constituyen en una forma de pensar ejercitada y actuada vez por vez.

En este punto, Ryle ubica en su lugar a las operaciones intelectuales y el sentido exacto de lo que entiende por operaciones mentales. Tales operaciones no están en la mente ya que se actúan públicamente y, en rigor, la mente no es un lugar ni siguiera metafóricamente. Así, nuevamente en contra del dogma del fantasma en la máquina, sostiene que

al describir las operaciones mentales de una persona no estamos describiendo un segundo conjunto de operaciones espectrales. Describimos determinadas fases de nuestra vida, esto es, los modos en los que esa conducta se lleva a cabo [...] los actos que observamos son, en sí mismos, los que se están haciendo con inteligencia [...] El sujeto es activo, corporal y mentalmente, aunque no simultáneamente en dos "lugares" distintos o con dos "máquinas" diferentes [...] [El lugar de la mente] está en el tablero de ajedrez, en el púlpito, en el escritorio del estudioso, en el estrado del juez, en el asiento del conductor de camiones, en el estudio y en la cancha de fútbol. En estos lugares la gente trabaja y juega, torpe o inteligentemente. $(2005$, p. 65$)$ 
190

\section{La teoría y sus formas discursivas}

Para Ryle las actuaciones que solemos relacionar con la razón, el intelecto, el entendimiento — como "teorizar" — no tienen ningún rango de exclusividad respecto a otras que despliegan "reglas del juego", y sus aptitudes no están reservadas a una élite porque las actividades que consideramos intelectuales comparten las mismas características de todas las actividades inteligentes como el ser "intencionales, habilidosas, cuidadosas, voluntarias, etc., considero tales operaciones como meras ocupaciones transitorias, parecidas a ocupaciones tales como hacer nudos, seguir una canción o jugar a las escondidas" (2005, p. 301).

Pero sin atribuirles algún tipo de anterioridad causal, es posible describir conceptos y actividades que consideramos intelectuales no por su carácter sino en razón de sus objetivos y finalidades. Aquellas actividades que denominamos intelectuales no responden a una forma distinta de actuar y se expresa tanto y tan bien mediante el despliegue de una conversación espontánea como en su forma meditada y cuidadosa, aunque le atribuyamos el carácter de intelectual solo a la segunda. Ambas actuaciones están atravesadas por una diferencia de propósito y finalidad, pero su especificidad no está dada por provenir o no desde un lugar denominado intelecto. Simplemente, "la forma de hablar corriente no tiene por objeto presentar las teorías..." (2005, p. 304).

La tendencia errónea de ubicar algunas actividades más cerca que otras del ámbito intelectual, que conduce a distinguir entre actividades intelectuales y no intelectuales, se afinca en la práctica social de la enseñanza que cultivó ciertas aptitudes por medio del aprendizaje proporcionado por el discurso didáctico, la lectio, que requiere de espacios e interacciones de tipo escolar. Ha sido esta práctica la 
que creó la idea de que, en efecto, existen facultades intelectuales separadas del resto y entronizó la figura del intelectual como aquel que ha recibido tal tipo de enseñanza, pero ello no da pie a concebir que se trata de acciones que vienen de un ámbito exclusivo y diverso a otros, pues todos ellos comparten los principios que rigen cualquier forma de actuación (2005, p. 305).

Por lo tanto, aquello que define el lenguaje científico que solemos definir como "intelectual” en realidad remite a propósitos, contextos, formas institucionales, actores, roles y textualidades específicas. La distinción de Ryle entre "pensar" (la tarea) y "pensamiento" (resultado de la tarea) apunta a algo parecido y es clave para remover el error de describir el "pensar" en términos prestados de sus resultados. De hecho, términos como "juzgar”, “abstraer”, "deducir”, "predicar", etc. "no denotan actos del pensar" (p. 307), porque el pensar no es accesible a la observación, pero sí las acciones expresadas en producciones como artículos, conferencias, informes... allí y solo allí se despliegan las operaciones analíticas, críticas, propositivas, no en otro lugar. En esencia, las actividades denominadas "intelectuales" comparten el mismo rasgo de sujetarse a reglas, como cualquier otra actividad, como ocurre con el juego o el trabajo.

Luego de remover la ilusión de un centro de operación con dedicación exclusiva para aquellas actividades a las que atribuimos el carácter de "intelectuales", Ryle (pp. 307 y ss.) inserta la distinción entre "construir una teoría", la tarea (tratar de obtener y lograr una teoría; equivale a viajar), y "tener una teoría”, el resultado (poseerla; equivale a llegar a destino). "Tener una teoría” es análogo a tener un lápiz. No quiere decir que haré algo con la teoría, pero estoy listo a producir un enunciado o una aplicación, de la misma manera que estoy dispuesto a usar el lápiz cuando la necesidad lo requiera. "Tener una teoría” irradia capacidades y posibilidades insospechadas, 
como la de explicarla y aplicarla, la de convocar teorías para explicar y predecir hechos, la de crecer en el lenguaje que hace posible comunicar teorías. Todas estas capacidades van juntas.

Pero las teorías, lo mismo que los planes, no se construyen meramente con el objeto de poder describirlas. El fin principal que se persigue al ofrecer esos ejercicios didácticos [...] es prepararse para poder utilizar esas lecciones en fines didácticos ulteriores. Colón no realizó sus viajes para poder agregar algo a lo que se decía en las lecciones sobre temas geográficos. Poseer una teoría o plan no es meramente ser capaz de decir en qué consiste. Ser capaz de describir una teoría, de hecho, ser capaz de hacer una cosa, a saber, su exposición didáctica. El dominio de los teoremas de Euclides no reside meramente en la posibilidad de citarlos, sino también en la posibilidad de contestar a objeciones y de determinar con su ayuda la medida de los campos. (p. 308)

Aunque no sabemos cómo, las teorías se transforman en "versiones que no son puramente didácticas" (p. 308) y eso tiene que ver con las capacidades deductivas expresadas en forma de predicciones (anticipar hechos futuros) y "retrodicciones" (explicación retrospectiva de hechos pasados): ambos aspectos son constitutivos del discurso didáctico, del aprendizaje de las teorías. Rememorar una teoría consiste en un acto didáctico que actualiza no solo la teoría de un científico, sino lo que habría dicho y hecho hoy y aquí con esa teoría. Otra de las capacidades que detona el "poseer teorías" es la capacidad comunicativa de enseñarlas, de dominar el lenguaje que hace posible transmitirla, es decir, nos da acceso a las capacidades propias de cómo hablar científicamente.

¿Cómo se construyen las teorías? El primer paso es fijarse en la producción textual que explican y describen las teorías. Esas formulaciones en prosa no contienen ni los procedimientos ni las observaciones ni los instrumentos, al menos, no todos aquellos que los autores desplegaron en su construcción. El segundo aspecto a tomar 
en cuenta consiste en que, en la tarea de construir teorías, intervienen personas con un cierto nivel de educación.

Pero, al margen y por encima de ambos aspectos, "la tarea de construir la teoría consistió en abrir sendas donde no las había” y a veces el "tener" o "poseer una teoría" subsume e invisibiliza todo aquello que ocurre cuando se la construye, presentando a los autores en plena y permanente posesión de sus teorías, oscureciendo las dudas y los diálogos interiores. Así, la tarea de construir una teoría implica otras tareas no explícitas y que no aparecen en los géneros discursivos que la comunican. Casi siempre quedan al margen reportes como la autopreparación del autor para comunicarla (al fin y al cabo, es una senda para facilitar el camino) y también la tarea didáctica de preparar a otros estudiosos.

Así, en esa senda el andar es más suave y veloz cuanto más trajinada por el autor y por otros que lo siguen, sin que el caminante advierta el volumen de los desbroces ni las irregularidades aplanadas. Toda teoría implica restricciones formales que apuntan a lograr el mínimo esfuerzo y la máxima eficacia tanto de parte de quien la comunica como de quien intenta comprenderla. Por ello, la presentación final de una teoría no condensa todos los elementos que intervienen en su construcción. Así el lenguaje de ambas fases, la de construcción y la de posesión, será distinto en complejidad y estilos enunciativos, pero, por lo regular, y por razones expositivas, se suele presentar primero el núcleo proposicional (el resultado) del que se derivan deducciones. Este orden es dado por restricciones discursivas a la hora de exponer la teoría, lo cual no solo trastoca lo que en realidad ocurre, sino que induce a pensar que, en la construcción de las teorías, intervienen principios anteriores. Lo que comunica primero es lo último en la línea de producción de tareas y si aparece así no tiene nada que ver con lo que de verdad ocurre en la construcción de teorías, sino simplemente en su exposición. 
Nos parece que Ryle invita a considerar la teoría como una realidad eminentemente discursiva. Se actúa en lo textual poniendo en escena todo aquello que se suele hacer y es posible comunicar cuando se comunica una teoría. Aunque la descripción de las teorías acuda a un vocabulario abstracto para construir enunciados que se articulan orgánicamente en forma de premisas y conclusiones no significa que esas operaciones ocurran en otro lugar que no sea el texto o invoquen otras realidades que no sean actuaciones de producción textual. Reconocer otra posibilidad conlleva a admitir que existen instancias internas, operaciones privadas y centros del "sumar y restar" anteriores que han comandado la construcción (p. 316), invocando nuevamente el dogma del fantasma en la máquina. Los términos "inferir", "ideas", "juicios”, "pensamiento", "tener ideas abstractas" tienen sentido solo como realidades operadas y actuadas en las diversas formas de discurso científico, en la exposición concreta; no refieren correlatos de algo que ocurre en la mente, sino en el discurso. Siguiendo su metáfora, estos términos forman parte del destino del viaje, una vez poseída la teoría, no del viaje mismo ("construir una teoría"), aunque su encadenamiento discursivo induzca la errónea idea de secuencia causal. En realidad, son producciones, constituyen una posesión en tanto ejecutoria exitosa, no un proceso ${ }^{42}$.

[El teórico] puede dar lecciones, porque ha terminado de aprender. Puede utilizar su equipo, porque se encuentra equipado. Como la tarea

42 Para Ryle las actuaciones lógicas inferenciales que van de una premisa a una conclusión no son "procesos”: “Paso’ es una metáfora equívoca. Es también equívoca cuando se utiliza para describir el cambio que se produce cuando una persona entra en posesión de una verdad que ha estado negociando durante un lapso prolongado o breve" (p. 323). El tiempo que lleva pasar de una premisa a una conclusión no indica la duración de pasar de una acción a otra; refiere un nivel precario de ejecutoria de una actividad compleja que se desarrolla como un todo y ello porque el lenguaje científico traslada el sentido primario de los términos "concluir", "deducir" y "probar" como verbos de éxito en lugar de asumirlos como verbos de posesión (p. 324). 
195

de entrenarse en el manejo del arma ha terminado, puede utilizarla ahora sin dificultades. Sus "pensamientos" son lo que ha obtenido ahora; no son las tareas sin las cuales no podría tenerlos ahora”. (p. 319)

\section{Comentarios y repercusiones pedagógicas}

Ryle aporta a la epistemología su potencial crítico en contra de la leyenda intelectualista, haciendo del "teorizar" una plataforma de actuación y desempeño constituida por capacidades y habilidades específicas susceptibles de ser aprendidas. "Teorizar" es una forma de actuación inscrita en una capacidad más amplia y compleja; al mismo tiempo, es producto del aprendizaje que convierte a los individuos y los colectivas en aptos para convocar, identificar, insertar y producir conceptos y teorías a diversos niveles. Por ello, su aporte es preponderantemente pedagógico antes que epistemológico, y se conecta con un marco rico de referencias filosóficas, lingüísticas y antropológicas. $\mathrm{Al}$ incluir el "teorizar" entre los comportamientos complejos que siguen reglas del juego observables solo a partir de aquello que hacemos públicamente a través de las interacciones, Ryle evoca, de inicio, la perspectiva de las Investigaciones filosóficas de Ludwig Wittgenstein ([1945] 2008), para quien la categoría "reglas del juego" es central, desplegándola y especificándola en las reglas del juego del lenguaje, las cuales entretejen el nombrar con el actuar, explican la constitución de las formas de vida y mueven a las personas entre sí.

Además, se conecta con los presupuestos de la pragmática lingüística de Austin (su contemporáneo y crítico) ${ }^{43}$, tan bien expresados en el título de su obra más conocida: Cómo hacer cosas con palabras ([1962] 1982) porque, para Ryle, el "teorizar" y la producción teórica constan entre lo que es posible hacer por medio del decir y sus formas

43 Austin produjo, apenas un año después de publicado el libro de Ryle, una revisión crítica del mismo. Ver Austin, J. (1950). 
específicas de discurso. El pensamiento acaece de afuera hacia adentro porque es aprendido, y algunas actuaciones, como el diálogo interior (del individuo consigo mismo), mediante el cual aprendemos y entendemos en interlocución con nosotros mismos, reproducen prácticas comunicativas y discursivas intersubjetivas. A la producción teórica le corresponde una "producción discursiva" a partir de reglas del juego públicamente desplegadas y, por ello, solo observables tal como los individuos interactúan y se comunican entre sí, sin considerar relevante el indagar mecanismos subpersonales que remiten a posibles dinámicas cerebrales o algún tipo de estructura lógica profunda subyacente ${ }^{44}$. Ryle contribuye, así, a romper el halo de misterio en torno al "teorizar" y a superar el enclaustramiento intimista de la producción teórica - considerada un suceso producido en la mente de los científicospara ubicarla en la escena de la producción pública debido a que accedemos a ella por medio del lenguaje y la comunicación, pulsando formas específicas de actuación discursiva.

La teoría es una producción, además de aprendida, comunicada; se trata de una producción discursiva ligada a formas específicas y convencionales de discurso (el discurso teórico) que usa el lenguaje abstracto y comprende otras tantas formas enunciativas específicas: una de ellas es el discurso didáctico mediante al cual aprendemos y transmitimos la producción teórica.

Al colocar la teoría y la acción de teorizar en la escena pública, Ryle anticipa desarrollos posteriores como el de la antropología simbólica desarrollada en la obra La interpretación de las culturas, de

44 Según el mismo Dennett, la apuesta y las preguntas de Ryle se enfocan en "lo que las personas hacen, acerca de lo que denomino el nivel personal del pensamiento... no acerca de cómo el cerebro hace posible que las personas hagan lo que hacen; esas cuestiones de nivel subpersonal estaban completamente fuera del área de su interés" (2005, p. 16). 
Clifford Geertz ([1978] 1983), en la que remarca el carácter público de los símbolos; y el interaccionismo simbólico de Erving Goffman, en su obra Ritual de la interacción ([1967] 1970), según la cual los intercambios e interacciones simbólicas tienen lugar mediadas por un marco público (frame) que les otorga sentido. Así, accedemos al "teorizar" observando no dentro de las personas sino fuera de ellas, a partir de lo que despliegan entre sí en sus interacciones e intercambios cada vez que desempeñan las reglas del juego y los roles del "teorizar" en el marco de sentido que norman y anticipan las expectativas de los interactuantes.

La perspectiva de Ryle es sumamente útil para la docencia universitaria porque ancla la enseñanza y el aprendizaje en el cultivo y posesión de capacidades complejas de actuación y ejecutorias discursivas públicas como son, de hecho, la investigación, la resolución de problemas y la creatividad para enfocar y delimitar preguntas e indagaciones. Ryle nos recuerda que la universidad es el lugar en el que se aprende ciencia "haciendo ciencia", desde, en sus términos, un "saber hacer" en acto y no tanto o no solo desde los conceptos, cuestionando la norma común de anteponer su posesión como condición primera e indispensable. Asimismo, nos recuerda que, desde el punto de vista del aprendizaje, "comprender es una forma de saber hacer" y, por lo tanto, no constreñida a los límites actuales del individuo sino sujeta a desarrollo y adiestramiento: todos pueden aprender ciencia haciéndola. Solo basta aprender las "reglas del juego", los desempeños.

De esa manera, Ryle es un punto de apoyo para otorgar sentido pedagógico al aula universitaria porque desautoriza el patrón académico expresado en el eslogan "primero la teoría y luego la práctica”, a partir de actividades expositivas que apuntan a transmitir los conceptos para luego esperar que se actúe conforme a estos, haciendo de la práctica el paso siguiente de la secuencia. Más bien, 
Ryle anima a imaginar que la "teoría” y el "teorizar" no transportan cursos de acción; se incluyen en estos, son en sí mismos "cursos de acción". El docente enseña a "teorizar" en el sentido de generar capacidades y habilidades para actuar las reglas del juego discursivas propia de las "teorías", como parte del obrar inteligente de la comunidad académica.

Aplicar la secuencia teoría-acción ocurrió no pocas veces también en escenarios de desarrollo local a lo largo de los años 70 y 80 del siglo pasado, donde cambiar la situación equivalía a "concientizar" inclinando, casi siempre, la balanza del lado de la trasmisión ideológica a cargo de sujetos con acceso privilegiado a los conocimientos. A su vez, la capacitación se entendió como el mecanismo de trasvase de nuevos conceptos con la esperanza de que ellos generarían nuevas formas de actuar por la misma fuerza de las teorías y las nociones. Ambas prácticas son formas desafortunadas de entender la docencia universitaria y el desarrollo porque, según hemos visto, el "obrar inteligente" no procede de esa manera y nos invita a ejercer la docencia y el conocimiento local desde aquella actuación y ejercicio que conocemos como "hacer ciencia" o "actuar el desarrollo" entendidos como formas de "saber hacer", a partir de capacidades y habilidades aprendidas en escenarios públicos y cursos de acción colectiva observables y al alcance de todos.

\section{La producción de teorías cientificas y los paisajes mentales de Magoroh Maruyama}

Su propuesta — no exenta de críticas, como veremos despuésnos parece relevante porque considera la pluralidad de posibles ejercicios de las teorías científicas y enriquece el marco descriptivo sin referirse, como es usual en la antropología, al contraste de otros tipos de conocimiento con el conocimiento científico: es precisamente su 
mirada preponderantemente dirigida a identificar cómo las diferencias culturales afectan el ejercicio y la producción de las teorías de la ciencia, lo que convierte su aporte en un lugar relevante y obligado para nuestra indagación. La ciencia, así, y por extensión, las teorías, obedecen a patrones diferenciados que regulan la producción de marcos éticos, epistémicos y cosmológicos también diferenciados.

\section{Modelos de causalidad y paisajes mentales}

Mediante la relectura y reorganización de sus hallazgos etnográficos anteriores en torno a cómo se producen las teorías en las ciencias físicas, biológicas y sociales, principalmente, Maruyama forja la certeza de la existencia de diversos patrones de cognición, percepción, conceptualización, diseño, planificación y toma de decisiones en los que operan epistemologías de la investigación diferentes relacionadas, a su vez, con características de personalidad y orígenes culturales diversos. Esa base etnográfica

evidenció que cada cultura contenía todos los tipos epistemológicos individuales encontrados en otros, aunque la distribución porcentual de los tipos varió. De igual forma, se hizo evidente que la misma teoría podría ser defendida por motivos epistemológicos diferentes y que muchas teorías aparentemente diferentes u opuestas podrían derivar de un solo tipo epistemológico y, por consiguiente, tener las mismas fallas... (1980, p. 589)

El concepto de "paisaje mental" es la noción clave que le permite reorganizar el material para caracterizar la producción de distintos tipos de teorías científicas como producidos y recirculados bajo las lógicas particulares de cada marco. Así, las teorías científicas o el perfil de tratamiento teórico de los problemas científicos se pueden clasificar según los siguientes cuatro modelos causales que conforman tipos o subtipos, niveles de evolución sucesiva que admiten 


\section{0}

combinaciones e hibridaciones ${ }^{45}$. Estos modelos causales, o "metatipos causales en teorías de la ciencia", son subyacentes en la constitución de los paisajes mentales correspondientes.

1.- Modelos de causalidad no recíproca, en los que las relaciones causales pueden ser probabilísticas o deterministas, y en donde no existen bucles causales; las relaciones causales obedecen a la ley transitiva.

2.- Modelos de eventos independientes, en los que los estados más probables del universo o de un sistema aislado son estados de distribución aleatoria de eventos independientes, cada uno con su propia probabilidad; existen relaciones no independientes y estructuras no aleatorias, pero son menos probables tendiendo a estar en estados más aleatorios, desestructurados y homogéneos.

3.- Modelos homeostáticos ${ }^{46}$ de bucle causal, en los que las relaciones causales pueden ser probabilísticas o deterministas y pueden formar bucles; las estructuras y los patrones de heterogeneidad se mantienen por los bucles causales homeostáticos.

4.- Los modelos de bucle causal morfogenético, en los que los bucles causales probabilísticos o deterministas pueden aumentar la heterogeneidad, generar patrones de relaciones mutuamente beneficiosas entre los elementos heterogéneos y elevar el nivel de sofisticación del sistema. (Maruyama, 1980, pp. 589-590)

Cada uno de estos modelos y sus variantes tiene un papel específico en momentos históricos diferentes. Así, los modelos del tipo 4 son los más nuevos en las ciencias "y complementan o reemplazan

45 La metodología que subyace en la identificación de estos modelos parten de investigaciones individuales y redes de investigación a cuyos resultados se aplicaron modelos matemáticos y simulación por computadora.

46 El término homeostático (homeostasis) proviene de las ciencias biológicas y define el conjunto de fenómenos basados en mecanismos de autorregulación en función de mantener el equilibrio o procesar situaciones de reequilibrio. La noción de autorregulación fue revisada anteriormente en la epistemología de Edgar Morin. 
cada vez más a los modelos homeostáticos que se desarrollaron durante la Segunda Guerra Mundial con el uso de sistemas de retroalimentación de corrección de errores en dispositivos, tales como la artillería antiaérea conectada con el radar por computadora” (p. 590). Entre otros casos, Maruyama ejemplifica cómo funcionan las explicaciones teóricas en torno al caso de la evolución civilizatoria y describe cómo proveen horizontes explicativos distintos, según los modelos de causalidad al que se adscriben, tal como se observa en la Tabla 10.

Tabla 10

Las teorías sobre la evolución civilizatoria según los metatipos causales

\begin{tabular}{|c|c|c|c|}
\hline $\begin{array}{c}\text { Modelos } \\
\text { de causalidad } \\
\text { no recíproca }(1)\end{array}$ & $\begin{array}{c}\text { Modelos } \\
\text { de eventos } \\
\text { independientes (2) }\end{array}$ & $\begin{array}{l}\text { Modelos homeostáti- } \\
\text { cos de bucle causal ( } 3 \text { ) }\end{array}$ & $\begin{array}{c}\text { Modelos } \\
\text { de bucle causal } \\
\text { morfogenético (4) }\end{array}$ \\
\hline $\begin{array}{l}\text { Supervivencia } \\
\text { del más fuerte } \\
\text { (competitividad) }\end{array}$ & $\begin{array}{l}\text { Capacidad de } \\
\text { sobrevivir las } \\
\text { rupturas }\end{array}$ & $\begin{array}{l}\text { Interacción } \\
\text { entre individuos } \\
\text { enmarcada en } \\
\text { una configuración } \\
\text { estable. }\end{array}$ & $\begin{array}{l}\text { Relaciones mutua- } \\
\text { mente beneficiosas } \\
\text { entre miembros } \\
\text { heterogéneos. }\end{array}$ \\
\hline $\begin{array}{l}\text { Dirección } \\
\text { homogénea de } \\
\text { la civilización. } \\
\text { La diferencia } \\
\text { es entre más } \\
\text { y menos } \\
\text { avanzados. }\end{array}$ & $\begin{array}{l}\text { Heterogeneidad } \\
\text { evolutiva. } \\
\text { Dirección im- } \\
\text { predecible de los } \\
\text { cambios. }\end{array}$ & $\begin{array}{l}\text { Evolución resulta- } \\
\text { do de interacción } \\
\text { entre elementos } \\
\text { heterogéneos. }\end{array}$ & $\begin{array}{l}\text { Interacciones que ge- } \\
\text { neran heterogeneidad } \\
\text { beneficiosa continua. }\end{array}$ \\
\hline $\begin{array}{l}\text { Sociedad } \\
\text { compuesta de } \\
\text { líderes } \\
\text { y seguidores. }\end{array}$ & $\begin{array}{l}\text { Sociedad que } \\
\text { irrumpe y } \\
\text { sustituye la } \\
\text { anterior. } \\
\text { Liderazgo de } \\
\text { ruptura; de } \\
\text { instauración. } \\
\text { La evolución al } \\
\text { no ser predecible } \\
\text { es peligrosa. }\end{array}$ & $\begin{array}{l}\text { Sociedad: } \\
\text { configuración } \\
\text { estable y satis- } \\
\text { factoria de las } \\
\text { interacciones. } \\
\text { Cultura: forma } \\
\text { de ajuste a las } \\
\text { condiciones locales. }\end{array}$ & $\begin{array}{l}\text { Cambios en varias } \\
\text { direcciones: evolución } \\
\text { multidireccional en la } \\
\text { misma condición local. } \\
\text { Relaciones de posición } \\
\text { con base en caracterís- } \\
\text { ticas no comunes antes } \\
\text { que por condiciones } \\
\text { óptimas. }\end{array}$ \\
\hline
\end{tabular}


202

\begin{tabular}{|c|c|c|c|}
\hline $\begin{array}{c}\text { Modelos } \\
\text { de causalidad } \\
\text { no recíproca }(1)\end{array}$ & $\begin{array}{c}\text { Modelos } \\
\text { de eventos } \\
\text { independientes (2) }\end{array}$ & $\begin{array}{l}\text { Modelos homeostáti- } \\
\text { cos de bucle causal ( } 3 \text { ) }\end{array}$ & $\begin{array}{c}\text { Modelos } \\
\text { de bucle causal } \\
\text { morfogenético }(4)\end{array}$ \\
\hline $\begin{array}{l}\text { Cambios } \\
\text { rápidos y } \\
\text { acelerados. } \\
\text { El cambio defi- } \\
\text { nido por la velo- } \\
\text { cidad (invención } \\
\text { y factores exter- } \\
\text { nos) pero no por } \\
\text { la dirección. }\end{array}$ & $\begin{array}{l}\text { Cambios } \\
\text { aleatorios. } \\
\text { Cambios por } \\
\text { sustitución y } \\
\text { saltos: lo que } \\
\text { viene reemplaza } \\
\text { lo anterior. }\end{array}$ & $\begin{array}{l}\text { Cuando la } \\
\text { configuración } \\
\text { cambia, sur- } \\
\text { ge una nueva } \\
\text { configuración. } \\
\text { El cambio se debe } \\
\text { a influencias } \\
\text { externas o internas. }\end{array}$ & $\begin{array}{l}\text { Cambios continuos, } \\
\text { graduales o rápidos. } \\
\text { Puede haber saltos o } \\
\text { superación de umbral. } \\
\text { Desarrollo de nuevas } \\
\text { formas: paso de la } \\
\text { energía del petróleo a } \\
\text { la eólica, por ejemplo. }\end{array}$ \\
\hline
\end{tabular}

Elaboración de los autores a partir de Maruyama (1980, pp. 590-591). Los textos en cursiva son resaltados de los autores con fines didácticos.

Sobre la base de estos tipos causales construye tipos epistemológicos de rango mucho más amplio que denomina "paisajes mentales", vale decir, "una estructura de razonamiento, cognición, percepción, conceptualización, diseño, planificación y toma de decisiones que puede variar entre un individuo, profesión, cultura o grupo social a otro". Los paisajes mentales configuran la tipología y características de las teorías científicas producidas. En la Tabla 11 Maruyama describe los tipos de paisaje mental con sus respectivos componentes y relaciones entre componentes y procesos.

Tabla 11

Tipos de paisaje mental y sus características ${ }^{47}$

\begin{tabular}{|l|l|l|l|}
\hline $\begin{array}{c}\text { Tipo de paisaje mental } \\
\text { (por sus siglas en inglés) }\end{array}$ & Componentes & $\begin{array}{c}\text { Relación entre los } \\
\text { componentes }\end{array}$ & \multicolumn{1}{|c|}{ Proceso } \\
\hline H (Jerárquico) & Homogéneo & Jerárquico & Clasificación \\
\hline I (Independiente) & Heterogéneo & Individual & Aleatorio \\
\hline S (Homeostático) & Heterogéneo & Interactivo & Homeostático \\
\hline G (Morfogenético) & Heterogéneo & Interactivo & Morfogenético \\
\hline
\end{tabular}

Tomado de Maruyama (1980, p. 591).

47 Nuestra traducción. Las palabras en cursiva son resaltados de los autores, pues las siglas en inglés no coinciden con las del castellano. 
Maruyama describe los rasgos característicos de cada uno de los paisajes mentales (a los que también denomina fases mentales), según las siguientes variables: filosofía general, ética, política ambiental, toma de decisiones, valores, estética, arquitectura, actividad social, religión, causalidad, lógica, conocimiento, percepción y cosmología. Para fines de nuestra exposición, y por razones didácticas, seleccionamos las siguientes variables: filosofía general, ética, conocimiento y cosmología, cuya descripción nos permitimos transcribir en el Cuadro 2 (1980, pp. 592-594).

\section{CUADRO 2: ASPECTOS DESCRIPTIVOS DE LOS PAISAJES MENTALES: FILOSOFÍA GENERAL, ÉTICA, CONOCIMIENTO Y COSMOLOGÍA ${ }^{48}$}

\section{Filosofía general}

H: Subordinación de la parte al todo. Existe una mejor manera para todos los individuos. Los principios universales se aplican a todos. La sociedad consta de categorías, supercategorías y subcategorías, estructuras, superestructuras e infraestructuras.

I: La sociedad es simplemente un agregado de individuos que piensan y actúan de manera independiente. Solo los individuos son reales.

S: La sociedad consiste en individuos heterogéneos que interactúan para el beneficio mutuo. Las interacciones mantienen un patrón armonioso de heterogeneidad o en ciclos. Las interacciones no son jerárquicas.

G: Los individuos diferentes interactúan para beneficio mutuo. Las interacciones no jerárquicas generan nueva diversidad, nuevos patrones y nueva armonía, y buscan nuevas relaciones para beneficio mutuo.

Nuestra traducción. 


\section{La ética}

$\mathrm{H}$ : El más fuerte domina a los más débiles. La ganancia de un individuo es la pérdida del otro (suma cero). Las decisiones deben tomarse por número de votos (dominación por cantidad) o por consenso (suposición de la existencia de una mejor solución para todos). Lo que beneficia a un mayor número de personas es mejor que lo que beneficia a un menor número de personas. Lo que es bueno para la mayoría también es bueno para las minorías. Las minorías pueden ser sacrificadas o ignoradas. Las diferencias generan conflictos, mientras que la misma fomenta la paz; por lo tanto, todas las personas deben ser iguales o similares, y las personas que son diferentes deben ser descartadas. Los débiles, los enfermos, los pobres deben morir; la raza superior o la clase social debe sobrevivir y gobernar. Aquellos que no cumplen con el "estándar" son anormales o desviados, y deben ser castigados o eliminados.

I: Todo el mundo debe ser autosuficiente. Ser pobre es culpa de la persona, y cada quien debe hacer lo que le corresponde. Las obligaciones sociales deben reducirse o eliminarse, y debe hacerse énfasis en la privacidad y el aislamiento. Las interacciones son dañinas (suma negativa). Se debe velar por el interés propio (las tabulaciones estadísticas se encargarán del resto y legitimarán a la persona como democrático).

S: Los individuos diferentes se ayudan los unos a los otros, pues las diferencias son deseables, necesarias y beneficiosas. La igualdad genera competencia y conflicto, mientras que la diversidad permite el beneficio mutuo. Todas las partes pueden beneficiarse de la interacción (suma positiva). Existe armonía entre diversos individuos, y esta armonía debe mantenerse.

G: Los individuos que son diferentes deben ayudarse los unos a los otros. Las diferencias son deseables, necesarias y beneficiosas. La igualdad crea competencia y conflicto, mientras que la diversidad permite el beneficio mutuo. Todas las partes pueden beneficiarse de la interacción (suma positiva). Debe generarse una nueva diversidad, y se deben 
buscar relaciones mutuamente beneficiosas con nuevos elementos para generar nuevos patrones de armonía.

$[\ldots]$

\section{El conocimiento}

H: Solo existe una verdad. Si las personas están suficientemente educadas o informadas, entonces estarán de acuerdo. Hay una mejor manera para todas las personas. El conocimiento de las reglas generales es superior al conocimiento de los detalles. Los hechos indican los principios universales. La realidad objetiva existe independientemente del perceptor. Las diferencias en la percepción se deben al error y a la falta de objetividad. La medición cuantitativa resulta básica para el conocimiento. Lo que no se puede medir resulta irreal o inválido.

I: Cada quien debe buscar las partes específicas de la información que son necesarias para la actividad; es inútil buscar principios universales o aprender más allá de nuestro interés.

S: La visión binocular nos permite ver tridimensionalmente, no porque los dos ojos vean lados diferentes, sino porque la diferencia entre las dos imágenes permite al cerebro calcular la dimensión que es invisible para ambos ojos. Del mismo modo, las diferencias subjetivas entre varias personas permiten calcular las dimensiones que son invisibles para todos. Esto se conoce como "visión poliocular"... o "análisis subjetivo cruzado". Los objetivistas consideran las diferencias como errores y descartan como irreales las partes de un objeto en las que los ojos no están de acuerdo. Este procedimiento elimina todas las partes del objeto, excepto las partes planas perpendiculares. El resultado es mucho menos que una visión monocular y es una distorsión grave de la realidad. "Apegarse a las partes en las que estamos de acuerdo e ignorar aquellas en las que no estamos de acuerdo" es un principio objetivista ampliamente practicado que distorsiona la realidad de una manera que va mucho más allá que el principio poliocular y una simple visión monocular. 
G: Igual que $S$.

[...]

\section{La cosmología}

$\mathrm{H}$ : El universo es homogéneo en el tiempo y el espacio. Los procesos son repetibles con la misma probabilidad en diferentes momentos y en diferentes lugares si las condiciones son las mismas (probabilísticas o deterministas).

I: El estado más probable es la distribución aleatoria de los eventos independientes, cada uno con su propia probabilidad. Las estructuras son no aleatorias e improbables y, por lo tanto, tienden a decaer. El universo se descompone.

S: Hay armonía entre los elementos heterogéneos. La armonía se mantiene porque las interacciones mutuas corrigen la desarmonía. La decadencia se puede contrarrestar. El universo se mantiene a sí mismo.

G: Las interacciones generan más diversidad, nuevas combinaciones de relaciones mutuamente beneficiosas, nuevos patrones y un creciente nivel de sofisticación de los sistemas biológicos, sociales y algunos sistemas físicos. El universo crece.

Adaptado de Maruyama, 1980, pp. 592-594. Traducción del autor.

\section{Comentarios finales}

La propuesta de Maruyama ha ganado difusión y reconocimiento, pero también ha recibido críticas, muchas de ellas muy radicales, que el mismo autor consigna en los comentarios de lectura recogidos al final de su artículo (1980, pp. 600-607). De esos comentarios destacamos las siguientes objeciones: 
- Sobresimplifica la realidad y corre el riesgo de construir estereotipos sobre la producción teórica y las epistemologías.

- Se trata de una propuesta en la que el modelo es más importante que la lógica, al punto de forzar que ciertas realidades que no encajan sean incluidas a la fuerza en el modelo.

- La producción teórica es parte de la discursividad pública y de los intercambios relacionales. La noción de paisaje mental, en cambio, predetermina la producción teórica sobre estos intercambios e interacciones concretas y situadas.

- Los paisajes mentales están atravesados por una carga de valoración moral, según la cual nadie quisiera pertenecer al paisaje $\mathrm{H}$ o I y todos quisieran formar parte del paisaje G.

Maruyama ejemplifica históricamente momentos, espacios y producciones de pensamiento que se atienen a uno u otro paisaje mental, mostrando, además, las posibles hibridaciones y entrecruces. Pero también aplica la noción de paisajes mentales a la caracterización de formas de pensar de religiones y culturas de largo recorrido, dando la impresión de que, en realidad, los tipos de paisajes mentales admiten un rango de aplicación que van más allá de las teorías tal como se actúan en la ciencia, es decir, la noción de paisaje mental parece, en realidad, aplicable a todo tipo de pensamiento.

Según nuestro punto de vista, Maruyama proporciona un marco descriptivo valioso para identificar y entender el funcionamiento de esquemas diferenciados de pensamiento que modulan la producción teórica. Muestra, además, que la ciencia es una realidad heterogénea constituida por prácticas sociales diversificadas que producen teoría desde horizontes constituidos por implicaciones lógicas, sociológicas, epistémicas, cosmológicas, políticas, éticas y ambientales también diversas. La razón de esta diversidad no estriba tanto en la especificidad de los objetos de conocimiento que carac- 


\section{8}

terizan las ciencias, sino que obedecen a las culturas y pertenencias que soportan prácticas científicas distintas.

$\mathrm{Su}$ alcance incluye preguntas sobre los aspectos relacionados con el rol de la herencia y los procesos posnatales y psicológicos, por medio de los cuales los paisajes mentales se cristalizan en los individuos hasta constituir marcos de pensamiento difíciles de ser removidos o transformados, pero sin proporcionar avances sustantivos al respecto. Respecto a los ámbitos de aplicación, Maruyama refiere el potencial pedagógico de su propuesta basada en los paisajes mentales para la educación temprana de los niños, aunque solo menciona de paso tal posibilidad sin desarrollarla; en efecto, la identificación de diversos paisajes mentales haría posible replicar y cultivar sus respectivas formas de pensar y de concebir la realidad y, así, enriquecer el desarrollo de múltiples capacidades y enfoques.

Su noción de paisaje mental fue tomada en cuenta por el mismo Morín (ver supra) como posible alternativa a la noción de paradigma en la búsqueda de encontrar esquemas y modelos más amplios para explicar la articulación entre las teorías, aunque se definió por este último, como vimos, en razón de su flexibilidad e indeterminación. Asimismo, en su artículo, encontramos un cierto parentesco y aire de familiaridad con la producción impulsada por la etnografía de la ciencia en torno a las actividades y procedimientos de los científicos, especialmente la de Latour y Woolgar (1979) basada en la etnografía del laboratorio; y la posterior de Knorr-Cetina (1999) sobre las culturas epistémicas en la ciencia y cómo ellas caracterizan la producción de conocimiento. Es necesario aclarar que el artículo de Maruyama no tiene los alcances de Latour y de Cetina, quienes evidencian que la ciencia es una palestra social constituida por fuerzas sociales en pugna que la tensionan en múltiples sentidos, como describe Martínez (2002) en su estudio sobre ciencia y feminismo. 
En realidad, los paisajes mentales aparecen como entidades idealizadas que cobran vida independiente al margen de los colectivos científicos concretos, de sus atributos de clase, género e intereses y de las prácticas que les dan vida y soporte real. Por ello, dan la impresión de que los paisajes mentales son esquemas previos a los que los científicos parecen adscribirse de manera pasiva, cual si se tratara de guiones preestablecidos con la capacidad de condicionar per se la producción teórica.

No obstante, creemos sin estar del todo seguros - y a partir de la trayectoria de asesor corporativo que marcó su biografía profesional ${ }^{49}$ - que su investigación coincidió, a la vez que se inscribió en la emergencia de marcos analíticos marcados por categorías como capital intelectual, inteligencia organizacional y gestión del conocimiento como claves del desarrollo empresarial y de la teoría organizacional, a fin de garantizar una producción flexible y atenta a los cambios del mercado y la sensibilidad de los usuarios, temas que coparon la escena desde fines de los años 80 hasta el presente. La adaptación a tales desafíos requeriría de la capacidad para identificar en las organizaciones paisajes mentales y culturas cognitivas, a fin de potenciar aquellas más abiertas y dispuestas a generar innovaciones en un marco de incertidumbre y de cambios constantes en las exigencias de los consumidores ${ }^{50}$.

49 Gracias a un perfil multifacético que combina las matemáticas, la antropología, la neurociencia y la psicología, Maruyama se desempeñó como consultor en alcaldías, compañías, corporaciones internacionales e instituciones públicas como la NASA, el Departamento de Comercio de Estados Unidos, Volvo, Michelin y la Federal Motors de Indonesia, entre otras.

50 Esa tendencia a caracterizar las modalidades y flujos del conocimiento en las empresas y corporaciones se refleja en aportes como los de Annie Brooking (1997) sobre el capital intelectual de las empresas; Gerrit Broekstra (1998) sobre la discursividad en la organización; e Ikujiro Nonaka e Hirotaka Takeuchi (1999) sobre las organizaciones creadoras de conocimiento, a partir de la dinámica innovadora de las compañías japonesas. 
Fue entonces que las instituciones públicas y la misma universidad comenzaron a mirarse y evaluarse a sí mismas en el espejo de las grandes corporaciones. Los temas en torno a cómo se producen, recirculan y se asumen las innovaciones y las instancias generadoras de conocimientos pertinentes y prácticas flexibles para enfrentar los retos de escenarios cambiantes constituyeron preocupaciones emergentes desde los 80 hacia el presente, también en las instituciones de educación superior. Aunque, valga decirlo, la comprensión de los factores que inciden en la producción diferenciada de teorías, según las diversas culturas académicas presentes en las instituciones de educación superior, constituye una línea de investigación con vida propia cultivada independientemente por la sociología de la ciencia y el conocimiento, al margen de la ola corporativa empresarial.

\section{Kieran Egan y la teoría como instrumento de conocimiento de la forma de comprensión filosófica}

La propuesta de Egan se inscribe en el diseño de una alternativa para un mejor manejo de la educación - y en el marco de la educación formal - en general, a la vez que fundamenta e impulsa un proyecto pedagógico que parte del siguiente principio: la humanidad ha creado formas de comprensión diferenciadas dotadas de instrumentos cognitivos específicos que se constituyen en mediaciones mediadoras de carácter simbólico basadas en el lenguaje y la capacidad mimética corporal. La educación debe garantizar el acceso y cultivo a todas las formas de comprensión y sus respectivos instrumentos intelectuales que hacen posible producir y compartir conocimientos. Así, los individuos replican en su ciclo de vida las transiciones y particularidades de las formas de comprensión producidas por la historia de la cultura.

La comprensión es una categoría polisémica que ha sido actuada de diversa manera a lo largo del desarrollo cultural occidental, 
generando tipos de comprensión que componen las capas que constituyen la compleja mente moderna. Esas formas son las siguientes: la comprensión mítica, la comprensión romántica, la comprensión filosófica, la comprensión irónica y la comprensión somática. Los instrumentos cognitivos de cada una constituyen la psique de los niños de afuera hacia adentro, es decir, modelan desde los intercambios sociales las capacidades de los individuos. La teoría es, entre otros, el instrumento intelectual y simbólico de un tipo de lenguaje propio de una forma de comprensión específica e históricamente situada: la comprensión filosófica.

La sistematización que ofrecemos a continuación consta de tres partes: la primera dará cuenta de los fundamentos pedagógicos y filosóficos de su proyecto; la segunda describirá las formas de comprensión y sus respectivos instrumentos cognitivos, desplegando con mayor detalle la forma de pensamiento filosófico y su correspondiente instrumento de conocimiento: la teoría, que constituye el centro de nuestro interés. La tercera y última parte ofrece algunas conclusiones e implicaciones pedagógicas en torno al cultivo del pensamiento teórico.

\section{La historia de la cultura y las bases pedagógicas para el cultivo de la imaginación}

Egan inicia dando cuenta del conflicto imposible de resolver entre tres herencias mutuamente incompatibles que se disputan el primado a la hora de articular el currículo sin resolver sus desafíos (2000, pp. 26 y ss.): la herencia durkheimiana, la herencia platónica y la herencia roussoniana, cuya brevísima caracterización es como sigue:

a. La herencia durkheimiana, que busca la socialización, esto es, la incorporación de los niños en los valores de su comunidad (acento ético) para salvaguardar la homogeneidad social. Hoy, 
la socialización se traduce en la necesidad de que los niños y jóvenes entiendan la sociedad en que viven y vislumbren su rol y lugar en ella; pero también se hace patente en las fuerzas que buscan homogeneizar el sujeto para garantizar su adaptabilidad, adecuación y conformidad con las expectativas sociales.

b. La herencia platónica (La República), que enfatiza los contenidos y el cultivo de la mente (la mente se convierte en aquello que aprende), por medio del manejo de contenidos ilustrados y formas de discusión sofisticadas (la academia) para acceder a una visión privilegiada de la realidad y discernir en medio de ella. Hoy se traduce en garantizar el acceso a la información y en el reconocimiento de la autoridad del experto para conectar el sujeto con las grandes discusiones y conversaciones que trascienden su ámbito inmediato.

c. La herencia roussoniana, que enfatiza los métodos (los métodos no son medios sino objetivos), a fin de adecuar el aprendizaje al ritmo, modalidades e intereses de los niños como ejes de la educación centrada en el individuo y sus intereses. Hoy se traduce en modular los contenidos de acuerdo a la situación individual y las condiciones evolutivas del sujeto y en proporcionar un marco de experiencias que motiven el aprendizaje. Los contenidos obedecen a los intereses temáticos que el sujeto configura a medida que indaga e investiga (aprendizaje por descubrimiento). No es importante lo que el estudiante sabe, sino lo que es capaz de hacer con lo que sabe. El enseñante no es autoridad sino un facilitador y motivador, un forjador de los entornos de aprendizaje.

Egan postula que es imposible impulsar las tres herencias a la vez; el intento de compatibilizarlas a toda costa es, en realidad, la causa de numerosos e irresolubles problemas en la educación. Por ejemplo, acceder a una visión privilegiada para la interpretación de 
situaciones y problemas (Platón) que coloca al individuo sobre los que carecen de dichas herramientas es incompatible con el modelo de educación que busca la adecuación e incorporación del individuo a la sociedad (Durkheim); de la misma manera que la propuesta de Rousseau (y la de Dewey) es incompatible con la de Platón porque en este último el sujeto debe acceder a conocimientos sofisticados independientemente de sus intereses, de tal manera que el desarrollo del conocimiento se impone sobre las condiciones psicológicas. Si en Rousseau y Dewey el desarrollo impulsa el conocimiento, en Platón el conocimiento impulsa el desarrollo. Finalmente, la herencia roussoniana es incompatible con la durkheimiana debido a que apunta a mantener a los niños (la niñez es en él una categoría compleja e idealizada) alejados de los valores sociales que están contaminados e interrumpen el libre desenvolvimiento de capacidades y de la individualidad. Por ello, la educación debe proteger cuanto sea posible al niño, retrasando cuanto sea posible su socialización para garantizar su libertad y creatividad.

Hoy, de hecho, ninguna práctica pedagógica se limita a ninguna de las tres herencias, y lo usual es intentar equilibrios y compromisos que, sin embargo, no logran subsanar las incompatibilidades de fondo. En este punto, Egan propone dejar a un lado estas herencias poderosas que se han fortalecido a lo largo del tiempo y plantea, más bien, asumir como categoría principal los "tipos de comprensión”. Solo así será posible integrar sin contradicciones los elementos clave de cada herencia porque, en efecto, cuando los niños y adolescentes acceden a esos tipos de comprensión y a sus respectivos instrumentos intelectuales en función de entender el mundo acaban socializándose. Así se trascienden los contenidos, se asegura la socialización y se proporcionan formas (métodos, itinerarios, no contenidos) de comprensión. La categoría "tipos de comprensión”, entendida esta última como un término polisémico, reemplaza la de 
"conocimiento", casi siempre impuesta en primer lugar, dando lugar a unos currículos más ricos, enlazados con muy diversas formas de comprensión, que suponen a su vez pistas de socialización, porque esos tipos y formas están enlazadas con desarrollos específicos e históricos de la cultura (2000, pp. 44-48).

Sobre la base de esta nueva categoría, Egan construye el andamiaje para una nueva teoría pedagógica basada en dos referentes conceptuales (pp. 48-56): el concepto evolucionista de recapitulación del inglés Herbert Spencer (1820-1903); y la perspectiva cultural del aprendizaje del soviético Lev Vygotsky (1896-1934). Ambos autores comparten el mismo sustrato basado en la noción fundamental de que "el niño sigue el camino de la cultura", aunque desde esquemas de pensamiento muy distintos. La teoría evolucionista de la recapitulación, cuyas implicaciones pedagógicas apoyó, por un momento, también John Dewey (1859-1952), supone la posibilidad de organizar y ordenar lógicamente el currículo replicando en los niños, y según su evolución psicológica, los contenidos y conocimientos de cada una de las fases del proceso de desarrollo (evolución) de la cultura, de tal manera que

Si el género humano ha dominado sus diversos tipos de conocimiento siguiendo un orden, en cada niño aparecerá una aptitud para adquirir estos tipos de conocimiento en el mismo orden. La educación debería ser una repetición en pequeño de la civilización. (Spencer, 1861, p. 76, citado en Egan, 2000, p. 49)

La idea de recapitulación fue desechada primero en razón de la urgencia de la sociedad industrial que demandaba acortar el camino del conocimiento y colocar a los niños en las necesidades del presente. Dewey llegó a desecharla por considerar que llevaría a una imitación innecesaria e irrelevante del pasado (Egan, 2000, p. 51) sobre el principio de que el progreso — punto de llegada - impone y sobrepone su saber sin necesidad de volver a andar el camino anterior. 
El segundo puntal del andamiaje teórico de Egan es el aporte de Lev Vygotsky ([1962] 1995), según la cual el aprendizaje es un proceso social que requiere de mediaciones simbólicas mediadoras, como los instrumentos intelectuales concebidos como realidades simbólicas del lenguaje de complejidad creciente como, por ejemplo, el lenguaje oral, la narración mítica, la teoría, la ironía... concebidas como funciones sociales externas simbólicas en el sentido de procesos interpsíquicos que operan desde la sociedad y la cultura hacia los individuos. El aporte de Vygotsky es solidario con la importancia de los tipos de comprensión transportados por instrumentos intelectuales que se constituyen de afuera hacia adentro en funciones psicológicas del individuo respecto a los contenidos.

Según Vygotsky, comprendemos el mundo mediante el empleo de unos instrumentos intelectuales mediadores que, a su vez, influyen profundamente en el tipo de comprensión que obtenemos. Por lo tanto, nuestro desarrollo intelectual no se puede entender adecuadamente en función del conocimiento que acumulamos o en función de unas etapas psicológicas como las de Piaget, sino que exige una comprensión del papel desempeñado por los instrumentos intelectuales disponibles en la sociedad en la que crece una persona. (Egan, 2000, p. 51)

Gracias a ello es posible entender la educación como el proceso de "interiorización de maneras históricamente determinadas y culturalmente organizadas de actuar sobre la información, la naturaleza social de las personas acaba siendo también su naturaleza psicológica" (Luria, 1979, p. 45, citado en Egan, 2000, p. 52). Vygotsky ofrece la oportunidad de reinterpretar y reposicionar la noción de recapitulación no en el sentido de recuperar contenidos y conocimientos de cada una de las etapas de la historia de la cultura, sino desde el desarrollo del lenguaje y sus correspondientes formas o tipos de comprensión regladas por instrumentos intelectuales. 
Ello deriva en un giro no menor que implica pasar de lo que comprendían nuestros antepasados a entender cómo comprendían nuestros antepasados: “... la mejor manera de concebir la educación es considerar que los individuos adquieren cada uno de estos tipos de comprensión en la mayor medida posible y siguiendo el mismo orden en que se desarrollaron históricamente" (Egan, 2000, p. 17). Esta postura que reinterpreta la recapitulación cultural distancia la propuesta de Egan de la Piaget, según la cual la comprensión y el conocimiento, en cambio, siguen la dirección opuesta — de adentro hacia fuera - que va del desarrollo del niño a los conocimientos. De esa manera, Egan afirma lo siguiente:

Mi propuesta es que la mejor manera de comprender la educación es verla como un proceso en el que el individuo recapitula los tipos de comprensión desarrollados durante la historia de la cultura. Este punto de vista implica que si estudiamos cómo se produjo históricamente esta transición podremos aprender algo que tenga un valor práctico para la educación; además, también podríamos comprender por qué esta transición es tan problemática para muchos niños y por qué hay muchos niños más que solo la realizan de una manera superficial. Si encontramos que en nuestra historia cultural la transición entre el conocimiento "preescolástico" y "escolástico" [...] ha sido problemática, las dificultades de los estudiantes no nos sorprenderán tanto; y si analizamos cómo se ha producido este desarrollo histórico podremos crear un currículo y unos métodos de enseñanza que apoyen este desarrollo en los estudiantes de hoy mejor que las formas actuales de enseñanza. (2000, p. 110)

\section{Formas de comprensión e instrumentos intelectuales. \\ La teoría: instrumento de conocimiento de la comprensión filosófica}

El concepto nuclear de tipos de comprensión es un concepto polisémico, vale decir, su significado varía y significa cosas dis- 
tintas según el contexto histórico y cultural concreto en el que se sitúa y el instrumento intelectual que despliega. De esa manera, comprender por medio del relato mítico no es lo mismo que comprender por medio de descripciones y enumeraciones de los viajeros o mediante conceptos y supuestos teóricos. Egan plantea que la historia de Occidente ha desarrollado cinco formas de comprensión a lo largo de su recorrido cultural: la comprensión mítica, la comprensión romántica, la comprensión filosófica, la comprensión irónica y la comprensión somática. De cada una de ellas identifica la etapa correspondiente de su desarrollo histórico cultural, establece su correspondencia con la etapa evolutiva del individuo, a la vez que describe el tipo de desarrollo del lenguaje que le corresponde, así como sus instrumentos intelectuales, formas discursivas y la redefinición de la realidad que cada una proyecta y genera.

La relación entre las formas de comprensión que se suceden unas a otras es acumulativa; es decir, la subsiguiente se apoya a la vez que recupera los instrumentos intelectuales de la anterior y sus formas discursivas, constituyéndose en su condición de posibilidad, pero con riesgos de pérdidas y rupturas. En la mente de los usuarios, sin embargo, no constituyen apartados inconexos y funcionan como un todo; $y$, antes que mentalidades independientes, constituyen perspectivas diferentes de la realidad. La Tabla 12 caracteriza los cinco tipos de comprensión identificados por Egan, sus instrumentos intelectuales y formas discursivas, así como la etapa histórico-cultural y la fase evolutiva del individuo que corresponde a cada una de ellas. 
Tabla 12

Tipos de comprensión e instrumentos intelectuales según Egan

\begin{tabular}{|c|c|c|}
\hline $\begin{array}{c}\text { Tipo de } \\
\text { comprensión }\end{array}$ & $\begin{array}{l}\text { Instrumentos intelectuales; } \\
\text { aspectos del lenguaje y formas } \\
\text { discursivas }\end{array}$ & $\begin{array}{c}\text { Etapa histórico cultural } \\
\text { y fase evolutiva }\end{array}$ \\
\hline Mítica & $\begin{array}{l}\text { Lenguaje oral } \\
\text { Narración y relato. Mito: expre- } \\
\text { sión de la mente poética. Metáfo- } \\
\text { ra y dualismo. } \\
\text { Comprensión totalizante }\end{array}$ & $\begin{array}{l}\text { Culturas orales no alfabetizadas. } \\
\text { Niños de } 8-9 \text { años. Despliegue del } \\
\text { aprendizaje deliberado. }\end{array}$ \\
\hline Romántica & $\begin{array}{l}\text { Lenguaje basado en la escritura } \\
\text { alfabética } \\
\text { Descripción, enumeración, clasi- } \\
\text { ficación, definición, heterogenei- } \\
\text { dad del espacio temporal. }\end{array}$ & $\begin{array}{l}\text { Sintaxis reflexiva de la Grecia } \\
\text { clásica. } \\
\text { Ejemplo más temprano: Historia, } \\
\text { de Heródoto (siglo V a C.). } \\
\text { Adolescentes de } 10 \text { a } 15 \text { años. }\end{array}$ \\
\hline Filosófica & $\begin{array}{l}\text { Lenguaje teórico. Lenguaje de la } \\
\text { ciencia } \\
\text { Recopilación de información } \\
\text { articulada con suposiciones e } \\
\text { hipótesis. } \\
\text { Integra el detalle y la generalidad. }\end{array}$ & $\begin{array}{l}\text { Nace en la Grecia clásica: Platón y } \\
\text { Aristóteles. } \\
\text { Ejemplo: Historia de Tucídides } \\
\text { (Grecia clásica). Busca: una teoría } \\
\text { de la historia. } \\
\text { Impulsada por la imprenta, la } \\
\text { ciencia e instituciones académicas. } \\
\text { Fase evolutiva: } 15 \text { años en adelante. }\end{array}$ \\
\hline Irónica & $\begin{array}{l}\text { Ironía: duda epistémica radical. } \\
\text { Conciencia de los límites del } \\
\text { lenguaje. } \\
\text { Densificación-complejidad del } \\
\text { vocabulario. } \\
\text { Tensiona teoría y narrativa; } \\
\text { teoría-imaginación artística. } \\
\text { Separación lo que se dice-lo que } \\
\text { se quiere decir. }\end{array}$ & $\begin{array}{l}\text { También nace en Grecia: Heráclito } \\
\text { y Sócrates. } \\
\text { Se expresa en el modernismo y el } \\
\text { posmodernismo. Kierkegaard y } \\
\text { Nietzsche. } \\
\text { Edad adulta }\end{array}$ \\
\hline Somática & $\begin{array}{l}\text { Lenguaje comunicativo prelin- } \\
\text { güístico intencionado: Mimesis } \\
\text { corporal } \\
\text { Supone conciencia individual } \\
\text { corporal y conciencia colectiva. } \\
\text { Tipos: juegos, gestos, movimien- } \\
\text { tos kinéticos intencionados. }\end{array}$ & $\begin{array}{l}\text { Etapa prelingüística de la } \\
\text { comprensión. } \\
\text { La capa cultural mimética se } \\
\text { fusiona con todas las formas de } \\
\text { comprensión. } \\
\text { Constituye la ironía del tipo de } \\
\text { comprensión irónica. }\end{array}$ \\
\hline
\end{tabular}

Elaboración de los autores a partir de Egan (2000, pp. 57-234). 
A continuación, describimos brevemente cada una de ellas, deteniéndonos con mayor detalle en la forma de comprensión filosófica que es aquella que despliega el conocimiento teórico como instrumento intelectual.

\section{LA COMPRENSIÓN MÍTICA}

Es propia de las culturas orales cuyo referente en Occidente son los mitos griegos. Evolutivamente, corresponde a la edad de entre 2 a 8 - 9 años, momento de repliegue de las disposiciones genéticas y despliegue del aprendizaje deliberado. Conforma el sustrato de todas las formas de conocimiento posteriores que retoman y proyectan de manera distinta muchos de sus elementos del lenguaje y la comprensión del mundo. Su instrumento intelectual está constituido por el lenguaje verbal, tal como se expresa en los relatos y narraciones míticas, expresiones de la mente poética.

El mito es una forma de relato (forma discursiva de estructura narrativa episódica) que conecta los elementos de la realidad, según los siguientes recursos de asociación entre contenidos:

a. Dualidad, que actúa y ordena las diferencias en oposiciones binarias, orientadas a comprender para actuar.

b. Fantasía, mediación que trasciende la experiencia y lo inmediato para reordenar el entorno, haciendo posible el control conceptual del mundo. La fantasía desmiente el dogma de la expansión progresiva del entorno que va de lo concreto a lo abstracto. El conocimiento recorre el camino inverso que va de lo abstracto a lo concreto y de lo lejano a lo próximo.

c. Abstracción, proceso según el cual el lenguaje va de lo abstracto a lo concreto; de lo general a lo particular. Lo abstracto consiste también en aquello no necesariamente consciente 


\section{0}

o formulable pero que está presente y organiza la realidad. Desmiente el mito del pensamiento concreto de los niños.

d. Metáfora, recurso del lenguaje poético mediante el cual se explica una cosa por medio de otra y constituye una forma de imaginación sofisticada de conexión entre realidades.

e. Imágenes que apelan a la memoria sensorial y a la simulación de escenarios. Supone una conexión del conocimiento con la sensorialidad (incorporación del conocimiento).

La forma de comprensión mítica es imaginativa y pragmática a la vez porque genera conocimiento para actuar en el mundo y un tipo de realidad basada en el carácter prototípico de los personajes y de las acciones. Es una forma de comprensión integradora porque capta el mundo como totalidad dada y conocida. El mito propone una realidad vivida cuyo vínculo con el sujeto es la intensidad emotiva (memoria) vinculante: en el relato todo lo que tiene significado cognitivo tiene significado afectivo. Lo sagrado es el valor más importante del mundo, que es una categoría afectiva antes que cognitiva.

\section{LA COMPRENSIÓN ROMÁNTICA}

Hace referencia a la conciencia reflexiva sobre el lenguaje propia de la Grecia clásica, y supone que la escritura genera recursos sígnicos y simbólicos que constituyen y dan forma desde sí mismos a nuevas maneras de pensar y proyectar el mundo. El ejemplo prototípico más temprano es la Historia de Heródoto (siglo V a. C.), cuyo rasgo particular es la colección de hechos maravillosos y exóticos ubicados en los límites del mundo. Esa etapa cultural responde, en los individuos, a la fase evolutiva que va de la preadolescencia a la adolescencia. La forma del lenguaje que soporta la comprensión romántica es la escritura alfabética que abre la posibilidad de producir registros detallados y memorias. 
Las estructuras discursivas e instrumentos intelectuales que median la asociación entre contenidos son, por ejemplo, la descripción, la enumeración, la clasificación, la definición y el análisis que constituirán el sustrato de la forma de comprensión filosófica basada en el acopio de información compleja en cantidad y cualidad. Esos recursos hacen posible tejer formas discursivas investigativas y exploratorias mediante la combinatoria de materiales heterogéneos distantes en el tiempo y en el espacio (a diferencia del tiempo y el espacio homogéneos del mito) como las descripciones etnográficas, la referencia indirecta y directa a testimonios, las enumeraciones y colecciones (el impulso adolescente por coleccionar elementos de una clase pero de variada procedencia en el tiempo y el espacio obedece al desarrollo de esta forma de comprensión).

El mundo se vive desde los detalles y el impulso del conocimiento apunta a lo remoto, lo exótico, lo extremo (para los adolescentes la reseña de récords es importante), lo sublime y los contextos. El personaje arquetípico es el héroe como autodidacta excéntrico. El tipo de comprensión romántica propone la realidad como entidad autónoma, fuera del alcance en primera instancia pero abierta al conocimiento, de tal forma que conocer es la mayor aventura y la actitud heroica más importante, a diferencia del mito que integra el mundo en una totalidad accesible y al alcance de la mano y de la acción. A la lógica del descubrimiento y la exploración le corresponde un aprendizaje por excitación e intensidad que invita a "probar los límites".

La forma de comprensión romántica proporciona una forma de abstracción basada en la descontextualización del detalle para referirlo y clasificarlo taxonómicamente según clases de similares $\mathrm{u}$ opuestos. A la vez, promete el acceso a los límites de la realidad y extremos de la experiencia, según un movimiento que va de afuera hacia adentro, de los límites al contexto inmediato. En los adoles- 
centes esta forma de comprensión es importante porque otorga los elementos que le permiten salvaguardar la identidad en medio de un mundo por conocer y de límites difusos. El valor sigue siendo la conexión afectiva con el mundo, pero también el sentimiento heroico de probar y tentar cognitivamente los límites del mundo.

\section{LA COMPRENSIÓN FILOSÓFICA Y LA TEORÍA}

Es el tipo de comprensión en el que se inscribe la teoría y, por lo tanto, el centro de nuestra atención. Nace también en la Grecia clásica y toma forma con el pensamiento de Platón y Aristóteles, dos de los exponentes de obligada referencia porque dan nombre y forma a lo que hoy reconocemos como pensamiento teórico. El producto narrativo prototípico y temprano es la Historia de Tucídides constituida en su ejemplo porque, a diferencia de Heródoto, no busca lo maravilloso, sino identificar los principios subyacentes que determinan los hechos; es decir, su objetivo no es acumular detalles, sino construir una teoría de la historia y establecer el o los principios que la mueven. Esta forma de comprensión corresponde a la fase evolutiva que va desde la adolescencia a los 20 años y la edad adulta. Históricamente, se consolida con la imprenta en la Ilustración, y hoy en la ciencia, práctica establecida e institucionalmente normada de indiscutible impacto en la vida social. La comprensión filosófica supone y es consecuencia de la alfabetización y requiere de una clase particular de formas comunicativas muy pautadas, así como de comunidades e instituciones que las sostienen y les otorgan credibilidad.

Toma forma en el pensamiento teórico sistemático y en sus instrumentos intelectuales, entre ellos las suposiciones e hipótesis. El pensamiento teórico se caracteriza por, al menos, los siguientes rasgos: a) generalización trazada por el enlace de los elementos de la realidad agrupados conceptualmente por nexos causales; b) provee 


\section{3}

una visión que trasciende los actores (el héroe romántico individual) a los agentes sociales que explica la historia a partir de causas y efectos; c) abierto a las anomalías y, por ello, flexible y dinámico; d) capaz de dotar de certidumbre ideológica que alimenta la identidad.

El pensamiento teórico se autopropone como visión privilegiada de la realidad y vía exclusiva hacia la verdad. Apunta a identificar lo recurrente, las reglas, leyes y principios generales subyacentes en la realidad, así como sus redes causales o conexiones basadas en los conceptos. Por lo tanto, despliega una reducción discursiva del mundo que genera un ciclo según el cual lo particular se subsume en lo general y lo general se enriquece o modifica con lo particular. El pensamiento teórico genera, así, esquemas que se transforman ante nuevas explicaciones que deben incluir y dar cuenta de las anomalías que surgen.

La comprensión teórica se basa en el primado de la comprensión escéptica sobre la tradición y, por lo tanto, es desestabilizante. El valor es de carácter epistémico (aquello que hay que comprender por medio de la teoría) y se expresa la verdad, que toma forma mediante términos teóricos. Lo abstracto, las teorías, adquiere realidad en el lenguaje que genera un mundo paralelo habitado por ideas. La verdad, al mismo tiempo, implica apego a un discurso formal atravesado por el lenguaje abstracto, sofisticado y que demanda la recopilación de información abundante y a conexiones de tipo argumental. El discurso filosófico apela a la prosa que articula corpus teóricos, así como preguntas y proposiciones metodológicas y empíricas. Ejemplo de la producción literaria propia de la comprensión filosófica son los tratados, los artículos científicos, los diccionarios y enciclopedias, cuya credibilidad está asociada a la pertenencia y respaldo de comunidades e instituciones académicas. La figura prototípica de la comprensión filosófica es el erudito, el científico que indaga y cuestiona, lo cual supone, si no totalmente, al menos el sacrificio de gran parte del sustrato poético y mítico. 


\section{4}

\section{LA COMPRENSIÓN IRÓNICA Y LA COMPRENSIÓN SOMÁTICA}

Son los dos últimos tipos de comprensión que desarrolla Egan, de tal modo que la comprensión irónica trasciende y deconstruye la comprensión filosófica; la comprensión somática, a su vez, ironiza y relativiza la comprensión irónica y toda forma de comprensión basada en el lenguaje verbal o escrito. La comprensión irónica también nació en Grecia y se desarrolló de la mano de pensadores como Heráclito y Sócrates, y se expresó en el modernismo y el posmodernismo; dos de las figuras más prominentes fueron Kierkegaard y Nietzsche. La ironía es el instrumento intelectual central y es una manera de pensamiento basado en la duda epistémica radical y en la conciencia de los límites del lenguaje. Supone la alfabetización, y un desarrollo tal de la escritura dotada de un altísimo grado de densificación y complejidad del vocabulario.

La ironía despliega un discurso de desconstrucción de lo aparentemente sólido y de refutación de sí mismo y de las narraciones canónicas. El pensamiento irónico supone la separación entre lo que se dice y lo que se quiere decir, articulando y tensionando entre sí la teoría y la narrativa, la teoría y la imaginación artística. Así, la realidad es reflejo del lenguaje y la reflexión sobre la realidad lleva siempre a la reflexión sobre el lenguaje; al mismo tiempo, hay una discrepancia insalvable entre afirmación y realidad. El personaje prototípico es el irónico, que se complace en deconstruir el orden, para crear el caos y romper los esquemas generales. Para el irónico el conocimiento es ilusorio y el mundo es contingente; por lo tanto, es inútil buscar certezas. Lo importante es pensar para ser radicalmente libre de los esquemas generales, por medio de la superación de la metafísica, de las cosmovisiones y las visiones finalistas de la historia y el cosmos. El mundo es el resultado de un conjunto de perspectivas diversas expresadas en narrativas. Para el irónico el valor no es epis- 


\section{5}

témico (la verdad), sino político (el consenso), porque es necesario convivir en medio de las perspectivas diversas.

La comprensión somática — para cuya descripción Egan se remite a la descripción de Merlin Donald (Origins of the Modern Mind) - corresponde a la etapa prelingüística que se anticipa y se fusiona con todos los tipos de comprensión. El instrumento intelectual es la mimesis corporal, acto simbólico comunicativo no lingüístico que se expresa, por ejemplo, en el juego, los gestos y los movimientos kinéticos intencionados. En tanto intencionado, es decir, dotado de una finalidad comunicativa, supera la imitación (forma de reproducción literal del referente) y la emulación (reproducción menos literal del referente).

Las características de la representación mimética son la intencionalidad, la generatividad (capacidad articulatoria de gestos), la comunicación (carácter público de la mimesis), la referencia a un significado (sígnica y simbólica) y la inclusión de una gama ilimitada de objetos. El punto de partida de la forma de comprensión mimética es la experiencia del cuerpo, experiencia singular por individual e intransferible, y se despliega más allá del lenguaje porque no es expresable en términos lingüísticos. De esa manera, la mímesis ironiza todos los tipos de comprensión basados en el lenguaje pues supone que existe un núcleo más allá de la posibilidad del lenguaje y fuera de su alcance, tal como es la experiencia del cuerpo. Al mismo tiempo, la experiencia corporal, en tanto individual e intransferible, constituye un nosotros corporal empático; más allá, más profundo y más amplio que el consenso propio de los usuarios del lenguaje.

\section{Implicaciones pedagógicas}

El proyecto pedagógico de Egan responde al contexto de las sociedades multiculturales contemporáneas, especialmente aquellas 


\section{6}

situadas en el mundo desarrollado que, al reconocerse como tributarias de la tradición intelectual de Occidente, ven en ella un repositorio de recursos de múltiples posibilidades para el cultivo de la imaginación a partir de los usos culturales del lenguaje. Entre los puntos a favor destacamos la distinción de múltiples formas de comprensión a las que les corresponden otras tantas formas de comunicación y que son propias de la tradición occidental, solo en apariencia monolítica. De esa manera, hace de la comprensión una práctica polisémica abierta a muchas maneras de concebir el desarrollo de la imaginación y del pensamiento, enlazando estos dos términos que no siempre logramos emparejar. Se debe valorar también el rol que Egan atribuye a la comprensión somática, constituyéndose en el metapunto de vista desde el cual redimensionar el alcance de los tipos de comprensión basados en el lenguaje.

Aunque construida en Estados Unidos, la propuesta de Egan tiene algo que decir y ofrecer a las experiencias educativas de los países emergentes como los nuestros, por varias razones. La primera consiste en que ofrece la posibilidad de identificar y remover el positivismo que persiste, sin ser nombrado, en la tradición educativa de cuño liberal que alimenta todavía gran parte del currículo, generando una cultura educativa aferrada a los contenidos propios de la ciencia y refractaria al cultivo de otras formas de pensar que remiten, por ejemplo, a la filosofía y a la religión ${ }^{51}$, para mencionarlos con los mismos rótulos del lenguaje positivista. Esta pesada herencia, que ancla la escuela al progresismo de fines del siglo XIX e inicios del XX, promueve el abandono y la superación de otros tipos de comprensión porque detienen el pro-

51 En nuestros contextos, el término religión alude directamente a las instituciones religiosas, como la Iglesia católica y las iglesias protestantes. No obstante, el sentido positivista del término religión es mucho más complejo y entraña los tipos de comprensión más elementales propios de las sociedades clasificadas como salvajes. El pensamiento mítico, por ejemplo, entra en esta categoría. 
greso y estorban el acceso urgente a los conocimientos y destrezas necesarias, además, para que los individuos puedan ejercer sus derechos como ciudadanos y contribuir al desarrollo de su nación.

La segunda razón, de alguna manera continua a la primera, consiste en la ventana crítica que proporciona Egan para valorar hoy las propuestas y programas de desarrollo del pensamiento de los años 90 cuyo objetivo era lograr operadores simbólicos capaces de lidiar con gran cantidad de información, propuestas que en su momento fueron consideradas como alternativa para las reformas educativas, al menos en Ecuador. Sin desmerecer su valor y el rol que jugaron, ni desconocer su apertura a la diversidad respecto a las formas de comprensión tal como propone, por ejemplo, la teoría de las inteligencias múltiples de Gardner, existe el peligro de que los programas de desarrollo del pensamiento tiendan a totalizar el currículo anclados en las operaciones e instrumentos intelectuales (nociones, conceptos, teorías, argumentos, subargumentos y sus respectivas formas proposicionales) que - ahora sabemos- son propios del pensamiento filosófico, con el peligro de dejar a un lado el cultivo de otros instrumentos y mediaciones simbólicas sobre las cuales se construye la posibilidad de interacción entre varios tipos de comprensión. El propósito de tales programas se vería más enriquecido con la siempre difícil apertura a la diversidad de tipos de comprensión, a partir de las cuales establecer un orden lógico y una secuencia pedagógica del currículo.

No obstante, el límite de Egan radica en la perspectiva multicultural que la alimenta, que inevitablemente apunta a subalternizar las diferencias epistémicas, trasladándolas al pasado para recuperarlas en el marco del ejercicio hegemónico del pensamiento científico en función de otras formas consideradas contemporáneas. América Latina, en cambio, es un continente que se debate entre la multiculturalidad y la interculturalidad, y en el que la pluralidad de los tipos 


\section{8}

de comprensión no son el resultado de la recapitulación del pasado de Occidente, instancia esta última ni de lejos la única tradición que ofrece posibilidades de diversidad de tipos de comprensión; ni en América Latina ni en Estados Unidos ni en Europa.

La interculturalidad latinoamericana — desde la perspectiva del Sur - asume que la pluralidad de tipos de comprensión son contemporáneos, están presentes entre nosotros y son recursos comunicativos y de pensamiento vivos ejercidos aquí y ahora por los pueblos y nacionalidades indígenas, por los afroamericanos y otros colectivos que disputan la contemporaneidad a otros tipos de pensamiento. Por lo tanto, no funcionan como capas previas que hacen posible otras subsiguientes. La oralidad (que incluye el pensamiento mítico), la conversación, las formas de deliberación colectiva, y otras que contemplan por supuesto el despliegue de formas letradas de pensamiento y comunicación, son posibilidades para ejercer en el presente la toma de decisiones respecto al futuro de su existencia colectiva diferenciada en medio de los cambios y de las amenazas.

El silenciamiento de estos tipos de comprensión no es producto de fallas y tareas pendientes de la recapitulación cultural, sino de la tarea hegemónica de ocultamiento y subalterización en torno a ellos, a fin de neutralizar su potencial de disputar y remover el presente civilizatorio. Esos tipos de comprensión son realidades simultáneas y constituyen destrezas colectivas atesoradas para discernir, deliberar y decidir. Pero la intervención de las relaciones de poder entre los tipos de comprensión propiciadas por el multiculturalismo y el eurocentrismo, en las que se inserta casi siempre el ejercicio del pensamiento teórico, se desplegará detalladamente a lo largo del próximo capítulo. 